\title{
The Impact of CBI Receptor on Inflammation in Skeletal Muscle Cells
}

\author{
Mansour Haddad (D) \\ Faculty of Pharmacy, Philadelphia \\ University, Amman, Jordan
}

Correspondence: Mansour Haddad Email Dr.man.haddad@gmail.com
Background: Various factors trigger the inflammatory response and cytokine activation in skeletal muscle. Inflamed muscle will exhibit significant levels of inflammation and cytokine activity. Interleukin-6 (IL-6), a pro-inflammatory cytokine, exerts pleiotropic effects on skeletal muscle. Endocannabinoid produced by all cell types binds to a class of $\mathrm{G}$ proteincoupled receptors, in particular cannabinoid $\mathrm{CB} 1$ receptors, to induce skeletal muscle actions.

Objective: The purpose of this research was to discover whether activation of cannabinoid CB1 receptors in L6 skeletal muscle cells may promote IL-6 gene expression.

Materials and Methods: L6 skeletal muscle cells were cultured in $25 \mathrm{~cm}^{2}$ flasks and quantitative reverse transcription-polymerase chain reaction (probe-based) utilised to quantify IL-6 gene expression levels among different treatment settings.

Results: Arachidonyl-2'-chloroethylamide (ACEA) $10 \mathrm{nM}$, a persistent selective CB1 receptor agonist, promotes IL-6 gene expression in a time-dependent manner. Rimonabant $100 \mathrm{nM}$, a selective cannabinoid CB1 receptor antagonist, blocks the impact of ACEA. However, insulin does not change IL-6 gene expression.

Conclusion: For the first time, a unique link between ACEA and IL-6 up-regulation has been established; IL-6 up-regulation generated by ACEA is mediated in skeletal muscle through cannabinoid $\mathrm{CB} 1$ receptor activation. As a result, cannabinoid CB1 receptors may be useful pharmaceutical targets in the treatment of inflammation and related disorders in skeletal muscle tissues.

Keywords: cannabinoid CB1 receptors, skeletal muscle, interleukin 6, ACEA, inflammation

\section{Introduction}

An endogenous signalling molecule is recognised as a crucial local regulator of tissue function. ${ }^{1}$ Cannabinoid modulates cellular processes via attaching to the two cell surface $\mathrm{G}$ protein-coupled receptor subtypes: $\mathrm{CB} 1$ and $\mathrm{CB} 2 .^{2}$ The $\mathrm{CB} 1$ receptor is the major receptor responsible for the effects of the endocannabinoid system in metabolic functions. ${ }^{3,4} \mathrm{CB} 1$ receptors are the most common GPCRs expressed in the brain, ${ }^{5}$ but are also expressed in peripheral tissues such as adipose, liver, pancreas and skeletal muscle. ${ }^{6,7}$ On the other hand, CB2 receptors were found to be predominantly abundant in immune system. Indeed, CB2 receptors were expressed within the spleen, tonsils, and thymus. ${ }^{8-10}$ Cannabinoid possibly plays many essential functions in physiological processes such as glucose homeostasis and insulin sensitivity. ${ }^{11,12}$ As of now, nothing is known about the pharmacology and biological function(s) of the CB1 cannabinoid receptor. ${ }^{11,13}$ Cannabinoid has recently been shown to have a considerable effect on inflammation in response to diverse stressors. ${ }^{11,13}$ Thus, 
cannabinoid systems emerge as major factors in inflammatory regulation processes. ${ }^{14,15}$ Targeting components, specifically the CB1 receptor, may aid in developing possible treatments for people with inflammatory diseases and related disorders, including insulin resistance in type II diabetes. ${ }^{12}$

Inflammation plays a key role in the pathogenesis of disorders involving skeletal muscle failure. ${ }^{16}$ Interleukin-6 (IL-6) is an inflammatory cytokine and mediator that affects immune and nonimmuno-regulation in a variety of cell types and tissues outside of the immune system, including skeletal muscle tissue. ${ }^{12,17-19}$ IL-6 is a physiologically active cytokine that regulates inflammatory responses, skeletal muscle cell proliferation, differentiation, growth, and metabolism. ${ }^{20}$ Recent data has shown that IL-6 is generated and released from skeletal muscle cells in the absence of inflammation and by complex signalling cascades. ${ }^{21-23}$ IL-6 is then believed to be a myokine because of its role in skeletal muscle growth, myogenesis, and energy metabolism regulation. ${ }^{23-25}$ Based on several investigational studies, prolonged IL-6 administration of mice results in insulin resistance in these animals. $^{21-23}$ Furthermore, investigations in both animals and humans have found that cannabinoids have also been connected with type II diabetes and obesity. ${ }^{26}$ Cannabinoids and CB1 receptor modulation do, however, influence downstream inflammatory pathways, in particular IL-6 in several tissues. $^{27,28}$

Cannabinoid modulates several inflammatory cells, such as gastrointestinal inflammation. ${ }^{29,30}$ Moreover, it appears that cytokine network processes are regulated by cannabinoid signalling. ${ }^{14}$ Cannabinoids enhance the secretion of IL-6 from different cells. ${ }^{14,15}$ Previous studies have demonstrated that skeletal muscle tissue produces IL- $6 .{ }^{12,19}$ Increasing evidence indicates that skeletal muscle is implicated in the inflammatory process via secreting cytokines. ${ }^{23}$ The effects of cannabinoids on muscle cell cytokine expression have not been evaluated. At the same time, cannabinoids are currently being explored for several disorders where inflammatory modulation is important. ${ }^{11,13}$ Generally, research indicates that CB1 receptors, in particular, play a key role in inflammation. $^{29,30}$ Indeed, stimulation of the $\mathrm{CB} 1$ receptor increases human macrophage, epithelial cell, and GI tract inflammation. $^{29,30}$ Extensive in-vitro and in-vivo studies have demonstrated significant pro-inflammatory and/or antiinflammatory actions for all cannabis activities. ${ }^{16,31,32}$ This receptor's function in skeletal muscle cells remains unknown.

Despite an emerging interest in the endocrine skeletal muscle, the role of the endocrine skeletal muscle's functional cannabinoid system in downstream inflammatory signalling is unknown. In an attempt to address this issue, a selective agonist of the cannabinoid $\mathrm{CB} 1$ receptors, ACEA and a selective antagonist of the cannabinoid CB1 receptors, rimonabant were investigated for their effects on IL-6 mRNA expression.

\section{Materials and Methods Materials}

Tocris Bioscience (UK) supplied the insulin, ACEA, and rimonabant, while Santa Cruz (USA) provided the dimethylsulphoxide reagent. Thermo Scientific Company (USA) supplied the Maxima Probe qPCR Master Mix (2X) and Thermo Scientific RevertAid First Strand cDNA Synthesis, while Qiagen (Germany) was the provider of the RNeasy Mini Total RNA Purification kits and RNaseFree DNase Set. Applied Biosystem (USA) provided Trizol and charcoal-stripped serum, while FBS (fetal bovine serum) was obtained from Capricorn Scientific (USA). Sigma Company (Germany) supplied horse serum, and Ham-F 10 was obtained from PAA Company (USA). Dulbecco's modified essential medium (DMEM) was supplied by Caisson (USA).

\section{Cell Culture}

The American Type Culture Collection (USA) provided the L6 skeletal muscle cell line from rats along with the myoblast cell line, originating from cells, maintained in the form of an attached monolayer culture in DMEM, with a high glucose level (4500 mg/L) with L-glutamate which had been supplemented by $10 \%(\mathrm{v} / \mathrm{v})$ heat-inactivated FBS and 100 $\mu \mathrm{g} / \mathrm{mL}$ of penicillin-streptomycin. Incubation of the cells took place at a temperature of $37^{\circ} \mathrm{C}$ using a $5 \%$ carbon dioxide atmosphere at $90 \%$ humidity. Passaging of the cells occurred at around $60 \%-70 \%$ confluency while changing the medium was carried out thrice weekly, as shown in Figure 1. The confluent cells underwent 14 days of further culturing in $25 \mathrm{~cm}^{2}$ flasks in order to allow myotubes to form, in alignment with the protocols outlined in my previous publications, ${ }^{48,49}$ albeit with minor modifications (Figure 1). After around two weeks of culturing, the $70 \%-$ $90 \%$ confluent myotubes were then exposed to $2 \%(\mathrm{v} / \mathrm{v})$ delipidated serum for a period of 5 hours before undergoing starvation for a further 19 hours. Figure 1 then shows that the cells were treated for varying periods of time $(1,3,5$, and 24 hours) with vehicle (0.1\% DMSO), rimonabant $100 \mathrm{nM}$, ACEA 10nM, and insulin 100nM. The ACEA and rimonabant cells had undergone pre-treatment using rimonabant for 

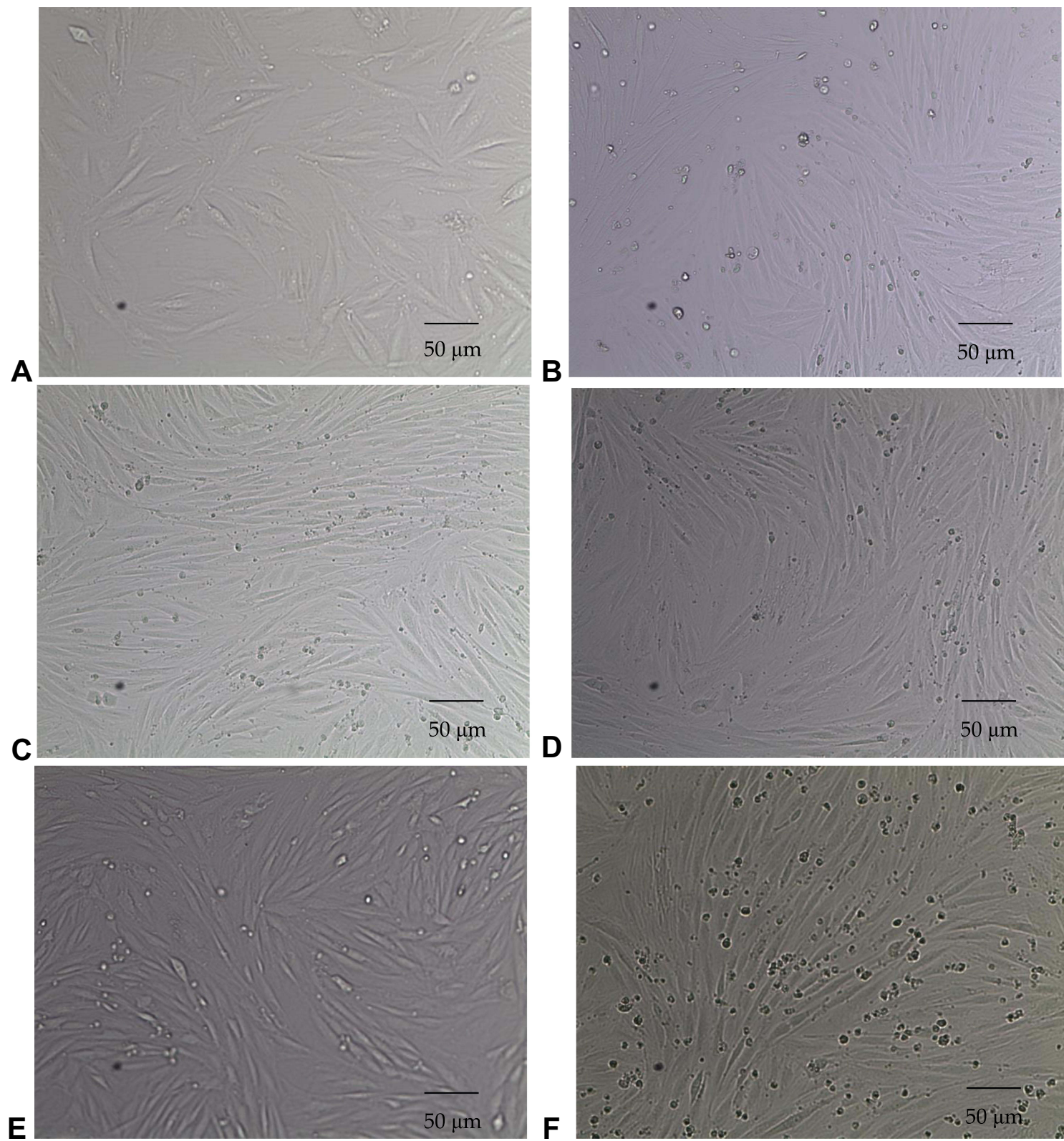

D
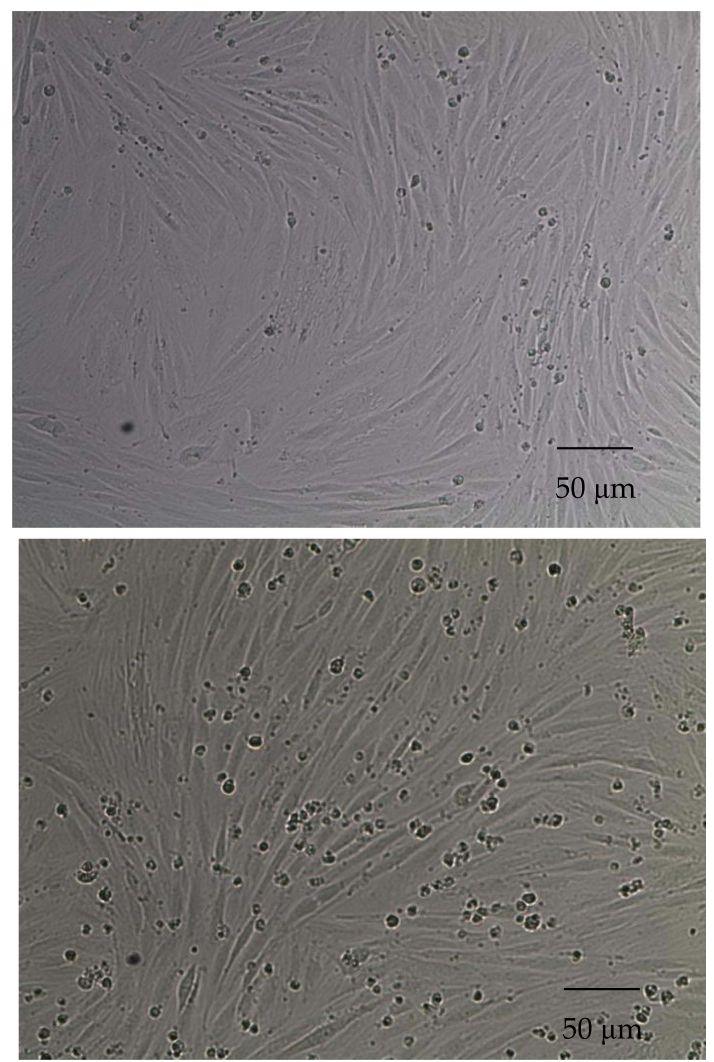

Figure I Images depicting L6 skeletal muscle myoblasts from rats, differentiated into L6 skeletal muscle myotubes (passage 7). (A) Myoblasts obtained on day 3 of the tissue culture in I0\% FBS Ham F-I0 media (IOX). (B) Cells obtained on day 4 of the tissue culture in $6 \%$ horse serum Ham F-I0 media (IOX). (C) Myotubes obtained on day 5 of the tissue culture in 2\% horse serum Ham F-10 media (IOX). (D) Myotubes obtained after 4 hours of tissue culture in $2 \%$ delipidated serum Ham F-I0 media (IOX). (E) Myotubes obtained after one hour of cell starvation in only Ham F-IO media (IOX). (F) Myotubes obtained after 19 hours of cell starvation in only Ham F-I0 media (I0X), (scale bar $50 \mu \mathrm{m})$.

10 minutes before adding ACEA. After the treatment, the cells were washed using ice-cold PBS, before lysing using Trizol (2mL per flask).

\section{Extraction of RNA and Synthesis of cDNA}

The L6 skeletal muscle cells of rats were placed in $25 \mathrm{~cm}^{2}$ flasks and scraped in $2 \mathrm{~mL}$ of ice-cold Trizol, whereupon the RNA was separated and isolated in line with the guidelines of the manufacturer. RNeasy purification columns (Qiagen, Germany) were then used to carry out the RNA clean-up and on-column DNAse digestion. A spectrophotometer (JENWAY Genova Nano) was then used to assess the concentration and purity of the RNA. In order to carry out the cDNA synthesis, a quantity of $500 \mathrm{ng}$ of total RNA underwent reverse transcription via RevertAid First Strand cDNA Synthesis in a process taking 5 minutes using a total volume of $20 \mu \mathrm{L}$ at a temperature of $25^{\circ} \mathrm{C}$, before the temperature was increased to $42^{\circ} \mathrm{C}$ for the 
Table I List of Gene Primer and Probe Sequences

\begin{tabular}{|l|c|}
\hline Gene & Sequences (5'3') \\
\hline IL-6 & $\begin{array}{c}\text { Probe: 5'-CTCTCCGCAAGAGACTTCCAGCCAGTT-3' } \\
\text { Forward primer: 5'-GCCCTTCAGGAACAGCTATGA-3' } \\
\text { Reverse primer: 5'-TGTCAACAACATCAGTCCCAAG } \\
\text { A-3' }\end{array}$ \\
\hline $\begin{array}{l}\text { TATA- } \\
\text { BOX }\end{array}$ & $\begin{array}{c}\text { Probe 5'- TCCCAAGCGGTTTGCTGCAGTCA -3' } \\
\text { Forward Primer 5'- TTCGTGCCAGAAATGCTGAA-3' }\end{array}$ \\
& Teverse Primer 5'- GTTCGTGGCTCTCTTATTCTCA \\
\hline
\end{tabular}

subsequent one hour period. Finally, the termination of the reaction took place for 5 minutes at $70^{\circ} \mathrm{C}$. Gene expression was then quantified using the relative standard curve approach on the basis of the TaqMan quantitative real-time PCR (qRTPCR). For this process, the preparation of the samples was carried out using a total reaction volume of $25 \mu \mathrm{L}$ (comprising $13 \mu \mathrm{L}$ Maxima Probe qPCR Master Mix $2 \mathrm{X}$ reagent, $1.5 \mu \mathrm{L}$ of forward primer $(10 \mu \mathrm{M}), 2.5 \mu \mathrm{L}$ Probe $(2 \mu \mathrm{M}), 1.5 \mu \mathrm{L}$ of reverse primer $(10 \mathrm{mM}), 5 \mu \mathrm{L}$ of water, and $5 \mu \mathrm{L}$ of cDNA). A 7500 fast real-time PCR system (Applied Biosystems, USA) was employed to complete the qRT-PCR analysis, while the determination of the gene expression was made by considering the relationship to the reference gene, TATA. Primer Express software (Applied Biosystems, USA) was used in the case of probes and primers for all genes, as shown in Table 1, with the design and synthesis performed by Integrated DNA Technologies, Inc. (USA). The standard curve approach was employed, using a slope ranging from -3.2 to -3.6 with $\mathrm{R}^{2}$ values exceeding 99\%, reflecting efficiency of amplification approaching $100 \%$.

\section{Data Analysis}

Data are presented in the form of mean \pm SEM following the generation of triplicate or quadruplicate wells from no fewer than three experimental groups. Data analysis of mRNA data employed one-way ANOVA and a Tukey's test. The GraphPad Prism, version 5.03 (GraphPad Software Inc) was used for all analyses, and the statistical significance level was determined to be $\mathrm{P}<0.05$.

\section{Results}

Cannabinoid CBI Receptors Induced IL-6 mRNA Expression in Rat L6 Skeletal

\section{Muscle Myotubes}

Treatment with ACEA $(10 \mathrm{nM})$ for 3 hours significantly upregulated the IL-6 gene expression $(p<0.05)$ but these responses were blocked by Rimonabant (100 nM) while treatment with Rimonabant $(100 \mathrm{nM})$ for 24 hours dramatically decreased the IL-6 gene expression $(p<0.01)$. ACEA $(10 \mathrm{nM})$ completely reversed this reaction $(\mathrm{p}<0.01)$ and insulin had no effect on IL-6 mRNA expression (Figure 2).

\section{Discussion}

This study's novel findings are that the IL-6 expression by skeletal muscle cells is escalated by stable cannabinoid analogue ACEA. The cannabinoid CB1 receptor subtype acts as the mediator for this ACEA effect. An analysis of available literature shows that this is the inaugural study exploring the cannabinoid analogue and its receptor subtype effect on inflammatory cytokine expression by skeletal muscle cells. Therefore, this study has the potential to add to available knowledge by presenting a novel contrivance for cannabinoid analogue's role in skeletal muscle cytokine network. Numerous papers provide proof to show that skeletal muscle cells collected from various species contain cannabinoid receptors. ${ }^{33}$ Apart from $\mathrm{CB} 1$ receptor gene expression, with nuclear receptors (NR4A) gene expression used as a functional downstream signalling readout of $\mathrm{CB} 1$ receptors (Data are not published yet), there is proof that functional cannabinoid $\mathrm{CB} 1$ receptors exist in the cells of the skeletal muscle. Cell surface cannabinoid receptors have also been noted to mediate numerous cannabinoid physiologic roles. ${ }^{34}$ In the present study, I present proof that the effect of cannabinoid analogue ACEA on IL-6 expression is mediated by the cannabinoid CB1 receptors subtype. From my results, it can be concluded that the IL-6 expression is increased by the selective agonist ACEA. This very strong agonist, at a concentration of $10 \mathrm{nM}$, has the potential to completely stimulate their cognate receptors in the absence of any substantial stimulation of the cannabinoid $\mathrm{CB} 1$ receptors subtype, rimonabant. When looked at together, these conclusions present robust evidence regarding cannabinoid CB1 receptors' role in the IL-6 upregulation initiated by ACEA.

To differentiate which receptor mediates this effect, ACEA was also used since ACEA is more selective for CB1 receptor than $\mathrm{CB} 2$ receptor by around 2000 times. $^{35}$ ACEA was found to increase IL-6 mRNA expression in rat L6 myotubes. Interestingly, this effect induced by ACEA was blocked by rimonabant, a selective $\mathrm{CB} 1$ receptor antagonist/inverse agonist. ${ }^{36}$ This finding suggests that IL-6 activation was mediated by activation of the CB1 receptor since $\mathrm{ACEA}$ is a selective $\mathrm{CB} 1$ receptor agonist 

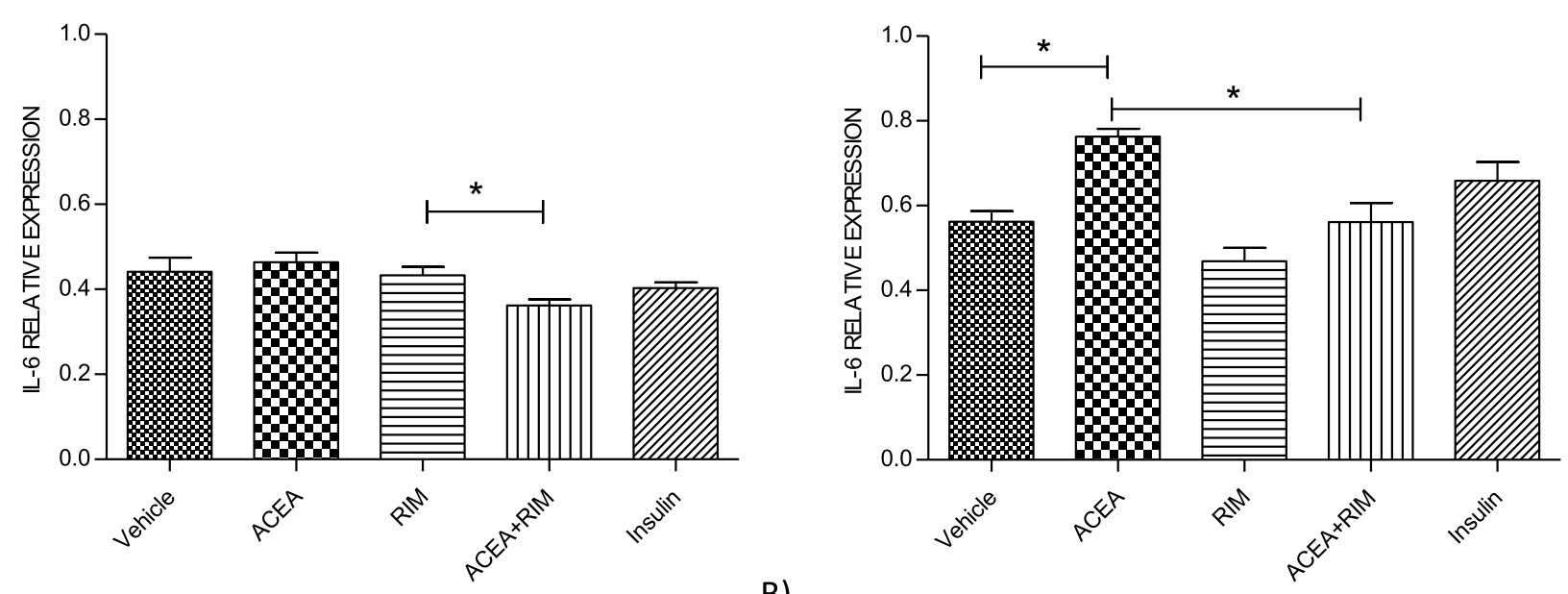

A)

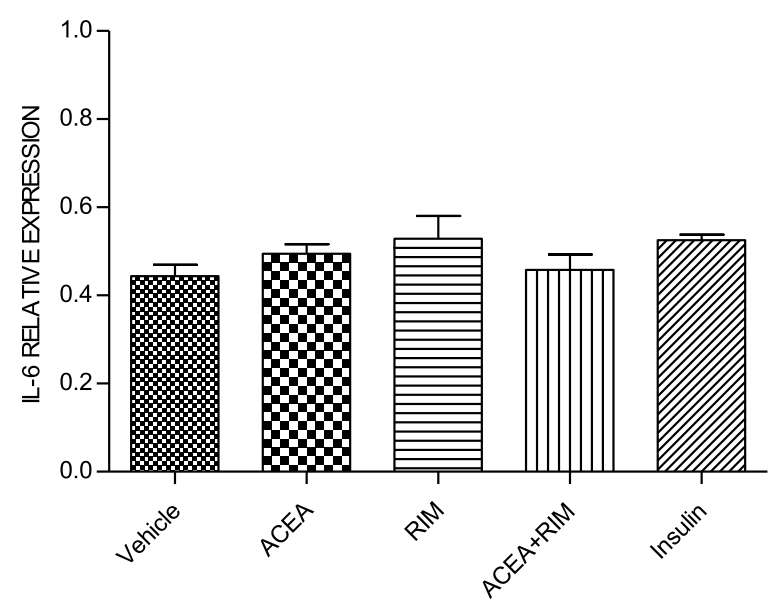

B)

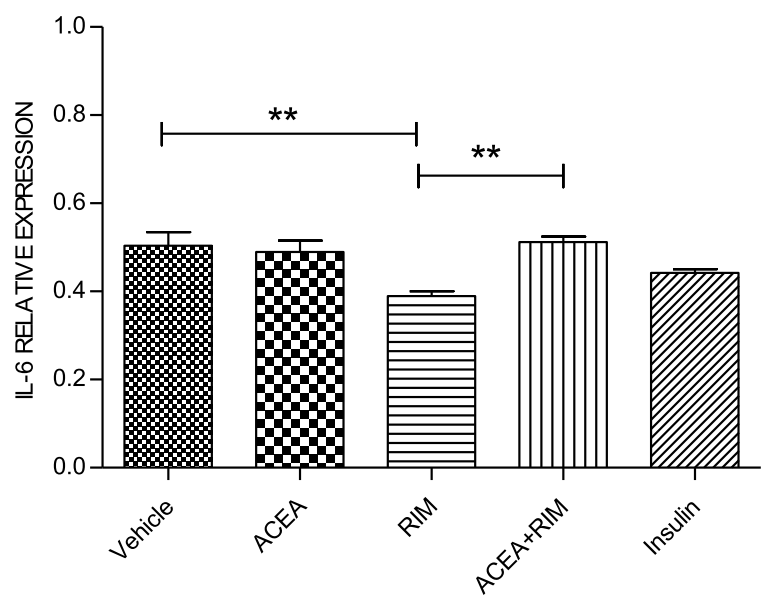

D)

Figure 2 L6 muscle myotubes-ACEA, Rimonabant, ACEA and Rimonabant, and insulin affect IL-6 gene expression; myotubes fed with delipidated serum. The stimulation time covered I to 24 hours, and IL-6 mRNA levels, relative to TATA-Box, was evaluated by quantitative real-time PCR (qRT-PCR) (I00 nM). The following scenarios explain the stimulation process conducted: (A) stimulation was done for I hour. (B) Stimulation was done for 3 hours. (C) Stimulation was applied for up to 5 hours. (D) Stimulation was applied for up to 24 hours. The data were reported as the mean \pm SEM of three separate groups. $(n=3 ; *$ denotes $p=0.05$ and $* *$ denotes $p=0.0$ I). Data were investigated by conducting one-way ANOVA test and Tukey's test.

Abbreviation: IL-6, Interleukin 6 .

at the concentration used in the present study. ${ }^{35}$ This study also provided strong evidence that $\mathrm{CB} 1$ receptor is a functionally active receptor in skeletal muscle. This is in line with a previous study that also found that CB1 receptor was found to be expressed in skeletal muscle. $^{11,12,33}$

Through the present study, it has been shown that when cannabinoid CB1 receptors are activated, the expression of interleukin-6 (IL-6) mRNA is escalated. This possibly crucial mechanism/process that has a vital influence on skeletal muscle function regulation is still unknown. Sometimes scholars perceive skeletal muscle as an endocrine organ. This is because skeletal muscle discharges an inflammation mediator known as Interleukin-6 and is responsible for increasing metabolism when human skeletal muscle is at rest. ${ }^{37}$ It has been concluded that obese individuals tend to have high levels of Interleukin6, which has also been linked to Type II diabetes. ${ }^{38}$ It has also been concluded that IL- 6 increases the oxidation of fatty acids and transportation of glucose in L6 myotubes. ${ }^{39}$ Cannabinoid agonist WIN55, 212 inhibited the release of IL-6 in the pancreatic acini of rats. ${ }^{40}$

In the present study, IL-6 mRNA expression in rat L6 skeletal muscle myotubes was triggered by ACEA stimulation of cannabinoid CB1 receptors. Such results correspond with those of another study that used Theiler's murine encephalomyelitis virus-infected astrocytes to show that anandamide $\mathrm{CB} 1$ receptor agonist potentiated the production of IL- $6 .{ }^{41}$ When these results are considered, it seems possible that the secretion of IL-6 
inflammatory cytokine in skeletal muscle myotubes and the consequent modulation of fatty acid and glucose metabolism is increased by the activation of the CB1 receptor. This implies that inflammatory cytokines modulation, especially IL-6, via the inhibition and/or activation of skeletal muscle CB1 receptors could potentially change the metabolism of fatty acids or glucose, insulin resistance, proliferation, differentiation, muscle growth, myogenesis and apoptosis, which could have a positive impact on obesity, diabetes, and sarcopenia. Moreover, the present study supported an evidence about the role of cannabinoid CB1 receptors in IL-6 regulation in L6 skeletal muscle cells, which is consistent with previous study that showed an increased IL-6 level in skeletal muscle-specific CB1Rknockout (Skm-CB1-/-) mice and demonstrated important benefits to insulin resistance, metabolism, and muscle mass in absence of skeletal muscle cannabinoid CB1 receptors in diet-induced obese and aged mice. ${ }^{42}$ And also, in this case, it has demonstrated that the pharmacological antagonism of CB1 by Rimonabant, but not its agonism by ACEA, exerts anti-inflammatory effects in dystrophic mice, ${ }^{43}$ which is line with this current research study.

The present study reports that the effects of ACEA (in Figure 2) can be noted in skeletal muscle cells. It could also be brought to the fore that the ACEA stimulations lasting 5 and 24 hours did not work, while it did on the 3-hour ones are on cells (Figure 2). This can be credited to the fact that cannabinoid CB1 receptors, being G-protein coupled receptors, require a specific period for coupling the G-protein before it can target the expression of the IL6 mRNA gene through inducing that transit downstream signalling pathway. Notwithstanding the reality that ACEA cell concentration does not have the capability to elucidate the difference in the effect of the 1, 5 and 24 hours treatment, a crucial factor may still be duration exposure. The indication that expression density/level of cannabinoid CB1 receptors in the skeletal muscle could meet a necessary condition for precise cannabinoid CB1 receptors activator action to change the cannabinoid $\mathrm{CB} 1$ receptor-responsive genes expression.

Determining the specific IL-6 transcripts at a precise time point that results in the production of IL-6 is a challenge. Nonetheless, it is vital to propose that the connection between protein synthesis and the content of RNA in skeletal muscle cells is not always a fixed linear correlation. ${ }^{44}$ It can be argued that the IL- 6 expression changes in inflammation as seen in the current study could be fleeting and therefore not be represented by the protein expression changes, and this is insignificant with regards to the development of inflammation as a reaction to stable cannabinoid analogue ACEA. The leading reason this study did not include the measurement of total protein is that the treatment duration was short, which in keeping with my main objective, was used for the identification of transcriptional events coming before inflation begins as a result of being activated by cannabinoid CB1 receptors. Previously, it has been indicated ${ }^{45}$ that the majority of the inflammatory transcripts studied (like IL-6) in skeletal muscle cells do not translate into protein during the timeframe specified. This is why future studies involving longer durations (ie, more than 24 hours) are suggested to allow for exploring the translated changes in reaction to treatment. This could deliver a better chance to explore the changes taking place at different intervals as durations are made longer (up to four days). On this basis, it becomes apparent that cannabinoid receptors, especially cannabinoid $\mathrm{CB} 1$ receptors, constitute crucial molecular targets for treating inflammation using cannabinoid-based therapies. Methods that use therapies based on cannabinoid receptors will rely on more studies exploring cannabinoid CB1 receptors in skeletal muscle signalling mechanisms, treatment duration and timing, and adverse and beneficial effects monitoring.

Surprisingly, in the current study, insulin $10 \mathrm{nM}$ did not change IL-6 expression in skeletal muscle cells using these time frame. This is not in line with other studies which showed that insulin induced IL-6 expression in adipocytes. ${ }^{46}$ Therefore, it is suggested in the future studies to try higher concentration and shorter time scale, in particular insulin is considered as an important hormone affected by inflammation and/or crosstalk with cannabinoid receptors in terms of biological and metabolic functions. ${ }^{11,12}$ Of note, the mechanism which is proposed on how cannabinoid CB1 receptor is regulated IL-6 might be through direct regulation (Gi-cAMP-PKA), ${ }^{27}$ or through indirect regulation of Akt via a Gi/PI3K-Akt/NF-kB pathway, ${ }^{28}$ or via PI3K/Akt/mTOR signaling, ${ }^{47}$ although further studies are required to explore these suggested mechanisms. It can be noted that the levels of mRNA could be a reflection of turnover and signalling protein transcription, although this might be happened at different time frame. Nevertheless, it can be suggested that there is a need for more studies assessing protein expression level (intracellular), release and activation 
(phosphorylation). Added to this, more work is required in exploring some functional measurements like interleukin release using L6 skeletal muscle cells or primary skeletal muscle cells. More work is also suggested to assess the direct effect of cannabinoid CB1 receptor on IL-6 using knock out of CB1 receptor in L6 skeletal muscle cells or to mimic the muscle physiology using knock out of CB1 receptor in primary myoblast isolated from mice or rats. This could provide more evidence with regards to this signalling. Other areas that could benefit from more studies include assessing more important genes connected to this signalling in skeletal muscle, including TNFalpha.

\section{Conclusions}

In the present study, I have demonstrated that when cannabinoid $\mathrm{CB} 1$ receptors are activated, the expression of IL-6 increases in a way that is influenced by time. Such findings deliver a novel mechanism characterised by cannabinoid analogue playing the role of a pro-inflammatory mediator in the skeletal muscle tissue. The findings from the present study also imply that there may be a possible therapeutic use of cannabinoid CB1 receptor antagonist at acute early states for skeletal muscle dysfunction related to inflammation. My findings point to skeletal muscle cell cannabinoid CB1 receptor as a therapeutic target, and expand its potential to include anti-inflammatory effects in diabetes, obesity, and sarcopenia.

\section{Significance}

This study describes a previously undiscovered signalling system in skeletal muscle cells that involves cannabinoid CB1 receptors. Furthermore, it explains a previously unknown process of muscle inflammation to reveal another possible treatment target for metabolic diseases associated with inflammation.

\section{Acknowledgments}

The author would like to thank the Scientific Research Support Fund/Ministry of Higher Education and Scientific Research in Jordan for their generous financial support of this project. The author would like to thank Cell Therapy Center-Amman, Jordan - for using qRT-PCR instruments (including A 7500 fast real-time PCR system; Applied Biosystems, USA). The author would like to thank all staff members at the Cell Therapy Center, Amman, Jordan.

\section{Author Contributions}

The author declares that this work was done by the author named in this article and all liabilities pertaining to claims relating to the content of this article will be borne by the author. All experimental work, study design, statistical analysis, interpretation of data, writing and revising the manuscript was performed by Mansour Haddad. The author has read and approved the final manuscript and has agreed on the journal to which the article has been submitted.

\section{Funding}

This research was funded by the Scientific Research Support Fund/Ministry of Higher Education and Scientific Research in Jordan [Project number is MPH/2/ 04/2013] at Philadelphia University (Amman, Jordan).

\section{Disclosure}

The author declares that he has no conflicts of interest.

\section{References}

1. Scheau C, Caruntu C, Badarau IA, et al. Cannabinoids and inflammations of the gut-lung-skin barrier. J Pers Med. 2021;11(6):254. doi:10.3390/jpm11060494

2. Stasiulewicz A, Znajdek K, Grudzien M, Pawinski T, Sulkowska AJI. A guide to targeting the endocannabinoid system in drug design. Int J Mol Sci. 2020;21(8):2778. doi:10.3390/ijms21082778

3. Lopez Trinidad LM, Martinez R, Kapravelou G, et al. Caloric restriction, physical exercise, and $\mathrm{CB} 1$ receptor blockade as an efficient combined strategy for bodyweight control and cardiometabolic status improvement in male rats. Sci Rep. 2021;11(1):4286. doi:10.1038/ s41598-021-83709-9

4. Pepper I, Vinik A, Lattanzio F, McPheat W, Dobrian A. Countering the modern metabolic disease rampage with ancestral endocannabinoid system alignment. Front Endocrinol (Lausanne). 2019;10:311. doi:10.3389/fendo.2019.00311

5. Tsou K, Brown S, Sanudo-Pena MC, Mackie K, Walker JM. Immunohistochemical distribution of cannabinoid CB1 receptors in the rat central nervous system. Neuroscience. 1998;83(2):393-411. doi:10.1016/S0306-4522(97)00436-3

6. Izzo AA, Sharkey KA. Cannabinoids and the gut: new developments and emerging concepts. Pharmacol Ther. 2010;126(1):21-38.

7. Starowicz KM, Cristino L, Matias I, et al. Endocannabinoid dysregulation in the pancreas and adipose tissue of mice fed with a high-fat diet. Obesity. 2008;16(3):553-565. doi:10.1038/oby.2007.106

8. Liu QR, Pan CH, Hishimoto A, et al. Species differences in cannabinoid receptor 2 (CNR2 gene): identification of novel human and rodent $\mathrm{CB} 2$ isoforms, differential tissue expression and regulation by cannabinoid receptor ligands. Genes Brain Behav. 2009;8 (5):519-530. doi:10.1111/j.1601-183X.2009.00498.x

9. Brown SM, Wager-Miller J, Mackie K. Cloning and molecular characterization of the rat $\mathrm{CB} 2$ cannabinoid receptor. Biochim Biophys Acta. 2002;1576(3):255-264. doi:10.1016/S0167-4781(02) $00341-\mathrm{X}$

10. Klein TW, Newton C, Larsen K, et al. The cannabinoid system and immune modulation. J Leukoc Biol. 2003;74(4):486-496. doi:10.11 89/jlb.0303101 
11. Haddad M. Do CB1 cannabinoid receptors regulate insulin signalling in rat primary skeletal muscle cells? J Phys Pharm Adv. 2013;3 (12):277-291.

12. Haddad M. What does rimonabant do in rat primary skeletal muscle cells? Biomed Pharmacol J. 2014;7(1):81-92. doi:10.13005/bpj/455

13. Wang Q, Perrard XD, Perrard JL, et al. Effect of the cannabinoid receptor-1 antagonist rimonabant on inflammation in mice with diet-induced obesity. Obesity. 2011;19(3):505-513. doi:10.1038/ oby. 2010.213

14. Haspula D, Clark MA. Contrasting Roles of Ang II and ACEA in the Regulation of IL10 and IL1beta Gene Expression in Primary SHR Astroglial Cultures. Molecules. 2021;26:10. doi:10.3390/molecules 26103012

15. Joffre J, Yeh CC, Wong E, et al. Activation of CB1R Promotes Lipopolysaccharide-Induced IL-10 Secretion by Monocytic Myeloid-Derived Suppressive Cells and Reduces Acute Inflammation and Organ Injury. J Immunol. 2020;204(12):3339-3350. doi:10.4049/ jimmunol.2000213

16. Zawatsky CN, Abdalla J, Cinar R. Synthetic cannabinoids induce acute lung inflammation via cannabinoid receptor 1 activation. ERJ Open Res. 2020;6(3):00121-2020. doi:10.1183/23120541.001212020

17. Laitano O, Robinson GP, Garcia CK, et al. Skeletal Muscle Interleukin-6 Contributes to the Innate Immune Response in Septic Mice. Shock. 2021;55(5):676-685. doi:10.1097/SHK.000000000000 1641

18. Villar-Fincheira P, Sanhueza-Olivares F, Norambuena-Soto I, et al. Role of interleukin-6 in vascular health and disease. Front Mol Biosci. 2021;8:641734. doi:10.3389/fmolb.2021.641734

19. Greco L, Russo V, Rapino C, et al. Characterization of Endocannabinoid System and Interleukin Profiles in Ovine AEC: cannabinoid Receptors Type-1 and Type-2 as Key Effectors of Pro-Inflammatory Response. Cells. 2020;9(4):1008. doi:10.3390/ cells9041008

20. Remels AH, Gosker HR, van der Velden J, Langen RC, Schols AM. Systemic inflammation and skeletal muscle dysfunction in chronic obstructive pulmonary disease: state of the art and novel insights in regulation of muscle plasticity. Clin Chest Med. 2007;28(3):537-552. doi:10.1016/j.ccm.2007.06.003

21. Londhe P, Guttridge DC. Inflammation induced loss of skeletal muscle. Bone. 2015;80:131-142. doi:10.1016/j.bone.2015.03.015

22. Begue G, Douillard A, Galbes O, et al. Early activation of rat skeletal muscle IL-6/STAT1/STAT3 dependent gene expression in resistance exercise linked to hypertrophy. PLoS One. 2013;8(2):e57141. doi:10.1371/journal.pone.0057141

23. Serrano AL, Baeza-Raja B, Perdiguero E, Jardi M, Munoz-Canoves P. Interleukin-6 is an essential regulator of satellite cell-mediated skeletal muscle hypertrophy. Cell Metab. 2008;7(1):33-44. doi:10.1016/j.cmet.2007.11.011

24. Steyn PJ, Dzobo K, Smith RI, Myburgh KH. Interleukin-6 Induces Myogenic Differentiation via JAK2-STAT3 Signaling in Mouse C2C12 Myoblast Cell Line and Primary Human Myoblasts. Int J Mol Sci. 2019;20:21. doi:10.3390/ijms20215273

25. Hoene M, Runge H, Haring HU, Schleicher ED, Weigert C. Interleukin6 promotes myogenic differentiation of mouse skeletal muscle cells: role of the STAT3 pathway. Am J Physiol Cell Physiol. 2013;304(2):C12836. doi:10.1152/ajpcell.00025.2012

26. Nagappan A, Shin J, Jung MH. Role of cannabinoid receptor type 1 in insulin resistance and its biological implications. Int $\mathrm{J} \mathrm{Mol} \mathrm{Sci.}$ 2019;20(9):2109. doi:10.3390/ijms20092109

27. Gonzalez-Mariscal I, Montoro RA, Doyle ME, et al. Absence of cannabinoid 1 receptor in beta cells protects against high-fat/highsugar diet-induced beta cell dysfunction and inflammation in murine islets. Diabetologia. 2018;61(6):1470-1483. doi:10.1007/s00125018-4576-4
28. Kim Y, Gautam S, Aseer KR, et al. Hepatocyte cannabinoid 1 receptor nullification alleviates toxin-induced liver damage via NF-kappaB signaling. Cell Death Dis. 2020;11(12):1044. doi:10. 1038/s41419-020-03261-8

29. Matias I, Gonthier MP, Orlando P, et al. Regulation, function, and dysregulation of endocannabinoids in models of adipose and beta-pancreatic cells and in obesity and hyperglycemia. J Clin Endocrinol Metab. 2006;91(8):3171-3180. doi:10.1210/jc.2005-2679

30. Bluher M, Engeli S, Kloting N, et al. Dysregulation of the peripheral and adipose tissue endocannabinoid system in human abdominal obesity. Diabetes. 2006;55(11):3053-3060. doi:10.23 37/db06-0812

31. Parker J, Atez F, Rossetti RG, Skulas A, Patel R, Zurier RB. Suppression of human macrophage interleukin-6 by a nonpsychoactive cannabinoid acid. Rheumatol Int. 2008;28 (7):631-635. doi:10.1007/s00296-007-0489-0

32. De Petrocellis L, Orlando P, Moriello AS, et al. Cannabinoid actions at TRPV channels: effects on TRPV3 and TRPV4 and their potential relevance to gastrointestinal inflammation. Acta Physiol. 2012;204 (2):255-266. doi:10.1111/j.1748-1716.2011.02338.x

33. Haddad. M. mRNA expression of GPCRs in rat skeletal muscle tissues. Int J Biol Pharm Allied Sc. 2014;3(10):2506-2536.

34. Lindborg KA, Jacob S, Henriksen EJ. Effects of chronic antagonism of endocannabinoid-1 receptors on glucose tolerance and insulin action in skeletal muscles of lean and obese Zucker rats. Cardiorenal Med. 2011;1(1):31-44. doi:10.1159/000322826

35. Hillard CJ, Manna S, Greenberg MJ, et al. Synthesis and characterization of potent and selective agonists of the neuronal cannabinoid receptor (CB1). J Pharmacol Exp Ther. 1999;289 (3):1427-1433.

36. Rinaldi-Carmona M, Barth F, Heaulme M, et al. SR141716A, a potent and selective antagonist of the brain cannabinoid receptor. FEBS Lett. 1994;350(2-3):240-244. doi:10.1016/0014-5793(94)00773-X

37. Glund S, Deshmukh A, Long YC, et al. Interleukin-6 directly increases glucose metabolism in resting human skeletal muscle. Diabetes. 2007;56(6):1630-1637. doi:10.2337/db06-1733

38. Spranger J, Kroke A, Mohlig M, et al. Inflammatory cytokines and the risk to develop type 2 diabetes: results of the prospective population-based European Prospective Investigation into Cancer and Nutrition (EPIC)-Potsdam Study. Diabetes. 2003;52(3):8 12-817. doi:10.2337/diabetes.52.3.812

39. Carey AL, Steinberg GR, Macaulay SL, et al. Interleukin-6 increases insulin-stimulated glucose disposal in humans and glucose uptake and fatty acid oxidation in vitro via AMP-activated protein kinase. Diabetes. 2006;55(10):2688-2697. doi:10.2337/ db05-1404

40. Petrella C, Agostini S, Alema GS, et al. Cannabinoid agonist WIN55,212 in vitro inhibits interleukin-6 (IL-6) and monocyte chemo-attractant protein-1 (MCP-1) release by rat pancreatic acini and in vivo induces dual effects on the course of acute pancreatitis. Neurogastroenterol Motil. 2010;22(11):1248-1256. doi:10.1111/ j.1365-2982.2010.01569.x

41. Molina-Holgado F, Molina-Holgado E, Guaza C. The endogenous cannabinoid anandamide potentiates interleukin- 6 production by astrocytes infected with Theiler's murine encephalomyelitis virus by a receptor-mediated pathway. FEBS Lett. 1998;433(12):139-142. doi:10.1016/S0014-5793(98)00851-5

42. Gonzalez-Mariscal I, Montoro RA, O’Connell JF, et al. Muscle cannabinoid 1 receptor regulates Il-6 and myostatin expression, governing physical performance and whole-body metabolism. FASEB J. 2019;33(5):5850-5863. doi:10.1096/fj.201801145R

43. Iannotti FA, Pagano E, Guardiola O, et al. Genetic and pharmacological regulation of the endocannabinoid CB1 receptor in Duchenne muscular dystrophy. Nat Commun. 2018;9(1):3950. doi:10.1038/ s41467-018-06267-1 
44. Millward DJ, Garlick PJ, James WP, Nnanyelugo DO, Ryatt JS. Relationship between protein synthesis and RNA content in skeletal muscle. Nature. 1973;241(5386):204-205. doi:10.1038/2412 $04 \mathrm{a} 0$

45. Scheler M, Irmler M, Lehr S, et al. Cytokine response of primary human myotubes in an in vitro exercise model. Am J Physiol Cell Physiol. 2013;305(8):C877-86. doi:10.1152/ajpcell.00043.2013

46. LaPensee CR, Hugo ER, Ben-Jonathan N. Insulin stimulates interleukin-6 expression and release in LS14 human adipocytes through multiple signaling pathways. Endocrinology. 2008;149 (11):5415-5422. doi:10.1210/en.2008-0549
47. Chou CH, Wei LH, Kuo ML, et al. Up-regulation of interleukin-6 in human ovarian cancer cell via a Gi/PI3K-Akt/NF-kappaB pathway by lysophosphatidic acid, an ovarian cancer-activating factor. Carcinogenesis. 2005;26(1):45-52. doi:10.1093/carcin/bgh301

48. Haddad M. Impact of Adenosine Analogue, Adenosine-5'-NEthyluronamide (NECA), on Insulin Signaling in Skeletal Muscle Cells. Biomed Res Int. 2021;2021:9979768

49. Haddad M. Impact of Adenosine A2 Receptor Ligands on BCL2 Expression in Skeletal Muscle Cells. Applied Sciences. 2021;11(5).

\section{Publish your work in this journal}

The Journal of Inflammation Research is an international, peerreviewed open-access journal that welcomes laboratory and clinical findings on the molecular basis, cell biology and pharmacology of inflammation including original research, reviews, symposium reports, hypothesis formation and commentaries on: acute/chronic inflammation; mediators of inflammation; cellular processes; molecular mechanisms; pharmacology and novel anti-inflammatory drugs; clinical conditions involving inflammation. The manuscript management system is completely online and includes a very quick and fair peerreview system. Visit http://www.dovepress.com/testimonials.php to read real quotes from published authors.

Submit your manuscript here: https://www.dovepress.com/journal-of-inflammation-research-journal 